Document downloaded from:

http://hdl.handle.net/10251/50251

This paper must be cited as:

Catalá Icardo, M.; Lahuerta Zamora, L.; Torres-Cartas, S.; Meseguer-Lloret, S. (2014). Determination of organothiophosphorus pesticides in water by liquid chromatography and post-column chemiluminescence with cerium(IV). Journal of Chromatography A. 1341:3140. doi:10.1016/j.chroma.2014.03.024.

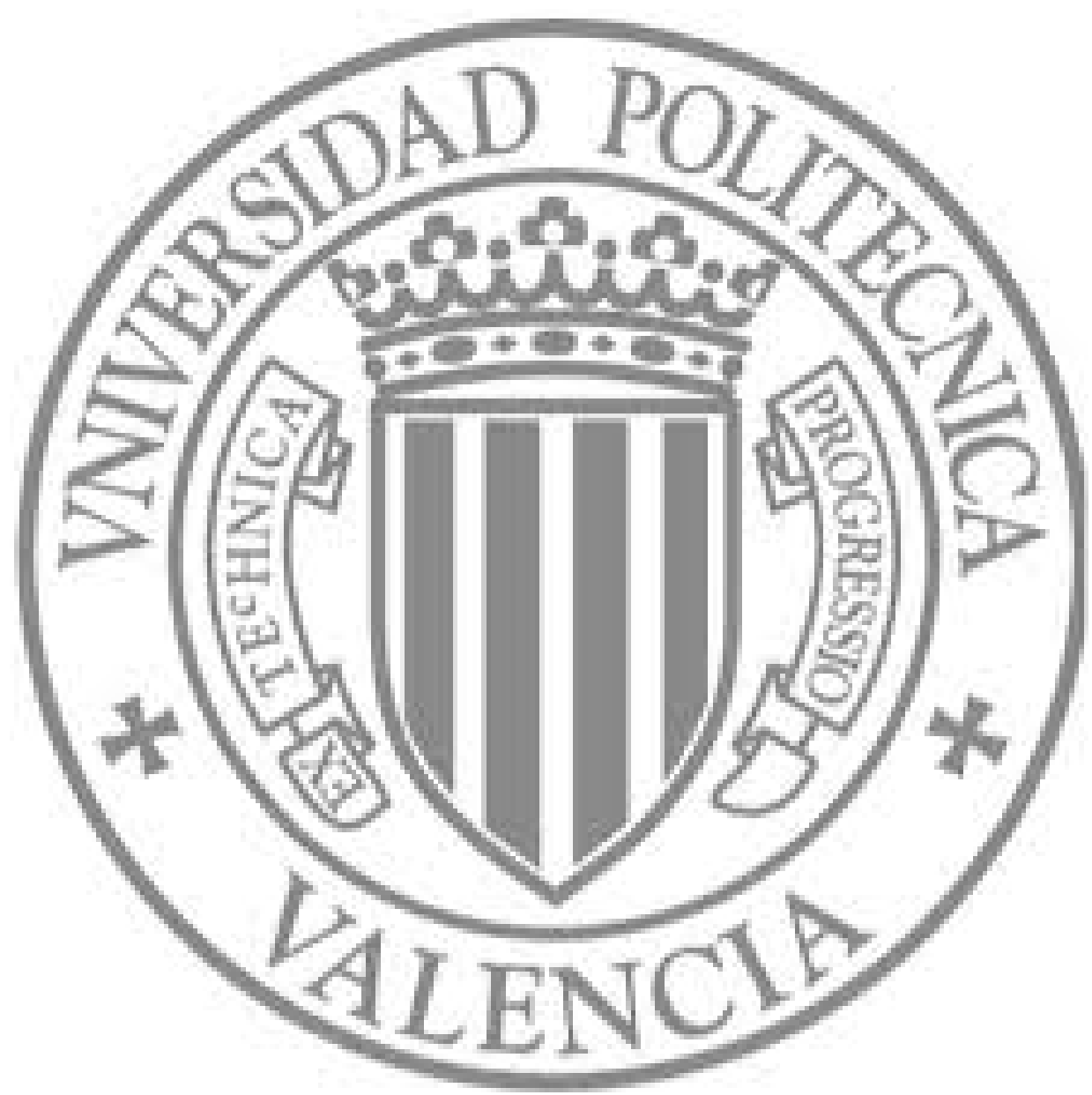

The final publication is available at

http://dx.doi.org/10.1016/j.chroma.2014.03.024

Copyright Elsevier 


\title{
Determination of organothiophosphorus pesticides in water by liquid chromatography and post-column chemiluminescence with cerium(IV)
}

Mónica Catalá-Icardo ${ }^{a}$, Luis Lahuerta-Zamorab, Sagrario Torres-Cartas, Susana Meseguer-Lloret. Instituto de Investigación para la Gestión Integrada de Zonas Costeras. Universidad Politécnica de Valencia. C/ Paranimf nº1, 46730 Grao de Gandía, Valencia, Spain.

${ }^{\mathrm{b}}$ Departamento de Farmacia. Universidad CEU-Cardenal Herrera. Avenida Seminario s/n, 46113 Moncada, Valencia, Spain.

${ }^{a}$ Corresponding author. Tel: ++34962849309; fax: ++34962849333.

E-mail address: mocaic@qim.upv.es

\begin{abstract}
A new, fast, selective and sensitive method has been developed for the simultaneous determination of nine organothiophosphorus (OTP) pesticides, namely omethoate, dimethoate, disulfoton-sulfoxide, methidathion, phosmet, malathion, diazinon, pirimiphos-methyl and chlorpyrifos. The pesticides were separated on a Kinetex C18 column by gradient elution with acetonitrile:water. A post-column basic hydrolysis of the pesticides and later a chemiluminescence (CL) reaction with cerium (IV) in acid medium was carried out. Hexadecylpyridinium chloride highly enhanced the CL emission. Under optimized conditions, linearity, precision, limits of detection and quantification, and accuracy were determined. Both selectivity and sensitivity were compared with those obtained with UV detection. In combination with SPE, limits of detection in the range 15-80 ng/L and 5-30 ng/L were obtained when $250 \mathrm{~mL}$ and $1000 \mathrm{~mL}$ of solution were treated, respectively. When applied to $250 \mathrm{~mL}$ of sample the inter-day precision of the method was between $3.5 \%$ and $7.3 \%$ and the intra-day precision between $2.9 \%$ and $6.0 \%$. The method was applied to determine OTP pesticides in spiked water samples from different origins: irrigation, river, sea, ground, spring, mineral and tap waters, being the percentage of recovery of added amounts near $100 \%$ form most of the pesticides.
\end{abstract}

Keywords: Chemiluminescence detection; Liquid chromatography; Organothiophosphorus pesticides; Water 


\section{Introduction}

Organophosphorus pesticides (OPPs) are esters of phosphoric acid with diverse substituents. OPPs are extensively used for plant protection because of their insecticidal activity, ability to combat a large number of pest species, availability, and low cost. Many OPPs are highly toxic and pose a serious risk to humans and animals [1] because they are cholinesterase inhibiting substances, and are even used as chemical warfare agents [2]. The threat to human health arises from either direct contact or through residue in food and contamination of drinking water [3]. Moreover, use of OPPs is preferred over other pesticides (e.g. organochlorine compounds) because they exhibit less environmental persistence [4,5].

A number of methods have been proposed recently for the determination of OPPs [6,7]. Gas chromatography (often coupled with mass spectrometry (MS)) and high-performance liquid chromatography (HPLC) (often coupled with diode-array detection or MS) are by far the most employed analytical techniques.

Because of the low concentrations and the complexity of some sample matrices, determining OPPs in water often requires a sample preparation step, which involves extracting target compounds and cleaning them up, prior to chromatographic quantitative determination. Diverse extraction techniques, such as liquid-liquid extraction, solid-phase extraction, solid-phase microextraction, stir-bar sorptive extraction, or single drop microextraction, among others, have been proposed for preparing water samples containing OPPs [7].

Chemiluminescence (CL) can be used as a detection technique for analysis of a broad diversity of compounds in different fields [8]. In fact, CL has been gaining increasing acceptance and has been used to determine OPPs residues in recent years [9-15]. Nevertheless, practical application of the HPLC-CL technique for the determination of pesticides is still uncommon. The reason is probably that not enough CL reactions are available, or that the mobile phase of HPLC is often incompatible with the CL reactions, resulting in difficulties for determination. Consequently, it is essential for analysts to expand the practical application of current CL reactions and explore new ones with high sensitivity and good compatibility with HPLC. It would then be possible to take advantage of the post-column CL reaction: the analytes are separated into their original form and the reaction products of the reaction do not require a long period of stability [16].

The CL phenomenon can solve some of the problems concerning the monitoring of pesticide, such as lack of sensitivity or selectivity, and it is a more economical alternative to other powerful detection systems, such as MS. 
To the authors' knowledge, until now only two HPCL-CL methods employing strong oxidants have been described for the determination of pesticides: benzenediols and 1,2,4benzenetriol [17], and pyrethroids [18].

The authors have previously published a flow injection analysis (FIA) - CL method for the determination of dimethoate in water samples [13]. The method developed was highly sensitive and, in general, good results were obtained. However, several compounds present in the environmental samples can often provide a similar response to the CL reaction and, therefore, they must first be removed. The aim of the present work was to develop an HPLC method, coupled with the post-column CL reaction, which would allow the simultaneous determination of several OTP pesticides with high sensitivity and selectivity. With this goal in mind, nine OPPs were selected, all of which were organothiophosphorus (OTP) compounds, in which the phosphorus component is also bonded to one or more sulfur atoms.

\section{Experimental}

\subsection{Materials and reagents}

Analytical standards (pestanal quality) of omethoate (OME, 98.5\%), dimethoate (DIM, 99.6\%), disulfoton-sulfoxide (DIS, 97.1\%), methidathion (MET, 95.8\%), phosmet (PHO, 99.9\%), malathion (MAL, 97.2\%), diazinon (DIA, 98.3\%), pirimiphos-methyl (PIR, 99.5\%) and chlorpyrifos (CLO, 99.9\%) were obtained from Fluka (Buchs, Switzerland). Table 1 shows the structural formulas of the nine organothiophosphorus (OTP) pesticides. Acetonitrile (ACN) and methanol gradient grade reagents for liquid chromatography were obtained from Merck (Darmstadt, Germany).

Individual standard solutions of OTP (1000 mg/L) were prepared by exactly weighing and dissolving in ACN. Furthermore, the standard solutions were protected against light and stored at $4^{\circ} \mathrm{C}$.

Working standard solutions were prepared daily in an aqueous solution containing acetonitrile $40 \%$, and were filtered through nylon membrane filters (0.22 $\mu \mathrm{m}$ particle size) from Phenomenex (Torrance, CA, USA), before injection into the chromatographic system.

Ultra pure water, obtained from a Milli-Q water purification system from Millipore (Bedford, MA, USA) was used. Mobile phases were filtered through a $0.20 \mu \mathrm{m}$ nylon (for water) or polytetrafluoroethylene (PTFE) (for ACN) membrane filter from Phenomenex and degassed with an ultrasonic bath. 
The solid phase pre-concentration (SPE) of water samples was carried out using Strata-X (polymeric reversed phase) $200 \mathrm{mg} / 6 \mathrm{~mL}$ cartridges from Phenomenex.

The ammonium cerium (IV) nitrate (Panreac, Barcelona, Spain), HCl (Scharlau, Barcelona, Spain), Hexadecylpyridinium chloride monohydrate (HPC) (Sigma, Steinheim, Germany) and $\mathrm{NaOH}$ (Panreac) were filtered through a Phenomenex filter membrane of nylon or PTFE (0.45 $\mu \mathrm{m}$ particle size) before pumping them into the chromatographic system.

\subsection{Instrumentation}

Chromatographic analysis was carried out on an HPLC equipment from Jasco Analytica (Madrid, Spain), composed of a PU-2089 quaternary gradient pump, an AS-2055 autosampler with a $100 \mu \mathrm{L}$ loop, a MD_2018 photodiode array detector and a CL-2027 chemiluminescence detector. The system was controlled using the LC-NETII/AFC interface also supplied by Jasco. Acquisition and treatment of data was performed using the ChromNAV software (version 1.17.01).

HPLC separation was performed with a Kinetex C18 100 x $4.6 \mathrm{~mm}$ (2.6 $\mu \mathrm{m}$ particle size) column from Phenomenex, in conjunction with a security guard UHPLC C18 from Jasco Analítica.

The reagent solutions for post column CL reaction were propelled by a Minipuls 2 peristaltic pump, provided with tygon pump tubes from Restec (Barcelona, Spain). Connections were carried out with PTFE coil of 0.5 mm i.d. from Omnifit (Cambridge, UK).

\subsection{HPLC procedure}

A scheme of the HPLC-DAD-CL system is shown in Fig. 1. A volume of $100 \mu \mathrm{L}$ of the OTP solution was separated at room temperature $\left(25^{\circ} \mathrm{C}\right)$ with a gradient elution program at a flow rate of $1 \mathrm{~mL} / \mathrm{min}$. The mobile phase consisted of ACN and water, and the gradient elution program was: $30-44 \%$ ACN (0-0.5 min), 44\% ACN (0.5-4.6 min), 44-76\% ACN (4.6-8.2 min), 76-88\% ACN (8.2-9.0 min), 88\% ACN (9.0-9.4 min). This was followed by a 5 min equilibrium period with initial conditions prior to the injection of next sample. The UV spectra were recorded between 190 and $400 \mathrm{~nm}$ in order to check the chromatographic system and confirm the elution of the analytes from the chromatographic column, as well as to compare the results obtained with both detection systems. The column effluent from DAD was first mixed, through a T-piece, with a solution resulted of the confluence of $0.6 \mathrm{M} \mathrm{NaOH}$ and $0.4 \% \mathrm{HPC}$, both at $0.45 \mathrm{~mL} / \mathrm{min}$. After the mixture, a hydrolysis reactor of $4 \mathrm{~m}$ PTFE coil was inserted. Next, the hydrolysed solution was mixed with the oxidant solution by means of a second T-piece placed immediately before the CL detector. The oxidant solution resulted of the mixture of a $1.310^{-3} \mathrm{M} \mathrm{Ce}(\mathrm{IV})$ and a $1.2 \mathrm{M} \mathrm{HCl}$ solution, both at $0.45 \mathrm{~mL} / \mathrm{min}$. The $\mathrm{CL}$ emission was recorded as the background blank signal (baseline) and the 
quantification of OTP pesticides was based on the peak area obtained due to the increase in the CL intensity when pesticides were injected.

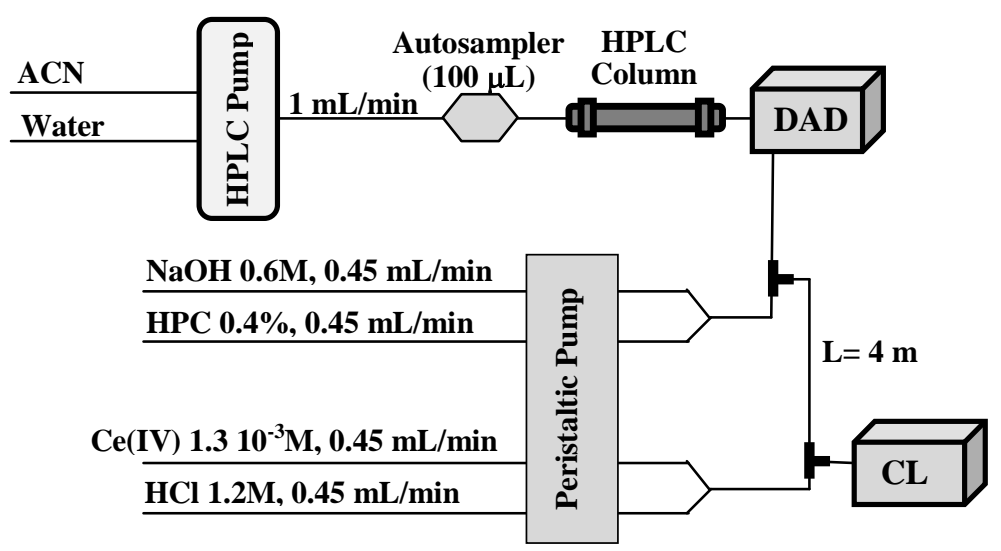

Figure 1. Schematic diagram of the HPLC-DAD-CL system used in the determination of organothiophosphorus pesticides. (DAD, photodiode array detector; CL, chemiluminescence detector; L, PTFE coil of $0.5 \mathrm{~mm}$ id $\mathrm{x} 4 \mathrm{~m}$ length)

\subsection{Water samples preparation and SPE procedure}

Water samples from different origins, namely irrigation, river, sea, ground, spring, mineral and tap waters, were tested. They were collected in plastic flask and stored in the dark at $4^{\circ} \mathrm{C}$ until analysis, performed before $48 \mathrm{~h}$. In order to remove sand and other suspected solid matters, samples were filtered over a $0.45 \mu \mathrm{m}$ membrane filter of cellulose acetate (Sartorius, Goettingen, Germany).

Spiking was done by adding the appropriate volume of standard to $250 \mathrm{~mL}$ of sample. Three replicates of each concentration were prepared. Extraction and preconcentration were achieved by solid phase extraction (SPE) with Strata-X cartridges. These were pre-conditioned with $3 \mathrm{~mL}$ of methanol, $3 \mathrm{~mL}$ of acetonitrile, $3 \mathrm{~mL}$ of methanol and $9 \mathrm{~mL}$ of water. Then, $250 \mathrm{~mL}$ of aqueous sample were passed through them at a flow rate of $6 \mathrm{~mL} / \mathrm{min}$. The cartridge was washed with $9 \mathrm{~mL}$ of water and dried with air for $20 \mathrm{~min}$. The retained OTP pesticides were eluted by means of gravity with $2 \mathrm{~mL}$ of ACN and finally under vacuum. Then, $2 \mathrm{~mL}$ of water were passed through the cartridge to recover quantitatively the ACN. Both volumes were collected in a volumetric flask of 5 $\mathrm{mL}$ that was filled up with water.

\subsection{Analytical figures of merit and method validation}

Analytical parameters including linearity ranges, correlation coefficients (r), limits of detection (LOD) and quantification (LOQ) and inter- and intra-day precision were evaluated as follows. 
For all the pesticides with HPLC-CL method eight points linear calibration curves were obtained by representing peak area versus standard concentration $(\mu \mathrm{g} / \mathrm{L})$.

LOD and LOQ were calculated on the basis of the equation $3 \mathrm{~S}_{\mathrm{b}} / \mathrm{b}$ and $10 \mathrm{~S}_{\mathrm{b}} / \mathrm{b}$ respectively, where $S_{b}$ is the standard deviation of the blank and $b$ is the slope of calibration curve obtained with standard solutions [19]. Both, LOD and LOQ, were estimated with the HPLC-CL method without and with SPE (250 $\mathrm{mL}$ and $1 \mathrm{~L})$.

The intra-day precision was determined by analysing, with the SPE-HPLC-CL method, seven replicates of OTP mixture standard solutions $(250 \mathrm{~mL})$ at $1 \mu \mathrm{g} / \mathrm{L}(1.5 \mu \mathrm{g} / \mathrm{L}$ for DIM and MAL and $2 \mu \mathrm{g} / \mathrm{L}$ for PIR) within a given day. The inter-day method precision was estimated by analysing seven replicates of the same solution on five different days, randomly executed in a 10days period.

In order to validate the SPE-HPLC-CL method, seven real water samples were fortified with the mixture of OTPs at two different levels, and three replicates of each level were analysed. Percentages of recovery of the added concentration were calculated. Moreover, results were compared with that obtained with DAD detection.

\section{Results and discussion}

\subsection{Optimization of HPLC system}

The mobile phase selected for separation should be compatible with the post-column CL reaction, because organic solvents often inhibit CL emission when strong oxidants are employed. Previous studies carried out in our laboratory [13] showed that 20\% ACN did not affect the CL detection of dimethoate, while methanol and ethanol inhibit light emission. Therefore, ACN:water was selected as the mobile phase. In order to avoid unnecessary consumption of reactants, this step was carried out using only DAD detection. PHO was monitored at $222 \mathrm{~nm}$, PIR at $250 \mathrm{~nm}$ and the rest of the OTP pesticides at $200 \mathrm{~nm}$.

Given the great difference in the properties of the selected OTPs in terms of polarity, gradient elution was necessary. The gradient elution profile was optimized to obtain a complete resolution of the nine OTPs within the shortest analysis time possible. To carry out the study, $20 \mu \mathrm{L}$ of the pesticides in $40 \%$ ACN were injected and a flow rate of $1 \mathrm{~mL} / \mathrm{min}$ was employed. The optimum gradient program with an ACN:water mobile phase, described in section 2.3, allowed complete separation in only $12 \mathrm{~min}$. 


\subsection{Optimization of the CL system}

To obtain the maximum CL emission, the effect of the variables involved in the post-column reaction was investigated by a univariate method. A preliminary study was performed using concentrations similar to those found for the FIA-CL determination of dimethoate [13]. A concentration of $3 \mathrm{mg} / \mathrm{L}$ of the pesticides was employed in this study. As a result, the starting conditions were: flow rate of HPLC separation $1.0 \mathrm{~mL} / \mathrm{min}$; flow rate of all post-column reagents $0.55 \mathrm{~mL} / \mathrm{min}$; $\mathrm{Ce}(\mathrm{IV})$ concentration $1.910^{-3} \mathrm{M}$; $\mathrm{NaOH}$ concentration $0.56 \mathrm{M}$; $\mathrm{HCl}$ concentration 1.4 M; HPC concentration 0.4\%; and, length of the hydrolysis reactor (L in Fig. 1) 4 m. With these conditions, and with an injection volume of $100 \mu \mathrm{L}$ to ensure maximum sensitivity, the optimization of the CL system was carried out.

The biggest difference between FIA-CL and HPLC-CL systems was the global flow rate: $18.7 \mathrm{~mL} / \mathrm{min}$ in the FIA-CL system and $3.2 \mathrm{~mL} / \mathrm{min}$ in the HPLC-CL system. The global flow rate in HPLC-CL depends on the mobile phase flow (usually $1 \mathrm{~mL} / \mathrm{min}$ ), and on the flow rates of the post-column reagents, which cannot be increased significantly without causing dilution of the pesticides.

The first optimized parameter was the length of the hydrolysis reactor. Lengths of 2, 4 and 6 $\mathrm{m}$ were tested. A two-meter reactor provided smaller signals probably due to an insufficient hydrolytic conversion. On the other hand, a six meter length produced double peaks, perhaps due to the formation of different chemical species in the longer hydrolysis time [20]. So, $4 \mathrm{~m}$ was selected as the reactor length.

Next, the flow rates of CL reagents (Ce(IV), $\mathrm{HCl}, \mathrm{NaOH}$ and $\mathrm{HPC}$ ) were studied (see Fig. 2a). These were simultaneously varied over the range $0.35-0.8 \mathrm{~mL} / \mathrm{min}$ and a value of 0.45 $\mathrm{mL} / \mathrm{min}$ for each channel was selected. Flow rates between 0.8 and $1.2 \mathrm{~mL} / \mathrm{min}$ for the HPLC separation were then assayed but $1 \mathrm{~mL} / \mathrm{min}$ was found to be the optimal value. Fig. $2 \mathrm{~b}$ shows the results obtained. In both cases, the behaviour of each pesticide was very different since several factors were affected by the flow rate variations: hydrolysis time, the kinetics of the CL reaction, and the dilutions of reagents. The behaviour of DIA, and especially MAL, was strongly influenced by the flow rate, and showed a minimum signal at intermediate flow rates. This could be because the hydrolysis of the pesticide is greater as the flow rate decreases, but these low flow rates have a negative effect on the CL reaction. The two processes can affect each pesticide in different ways. 


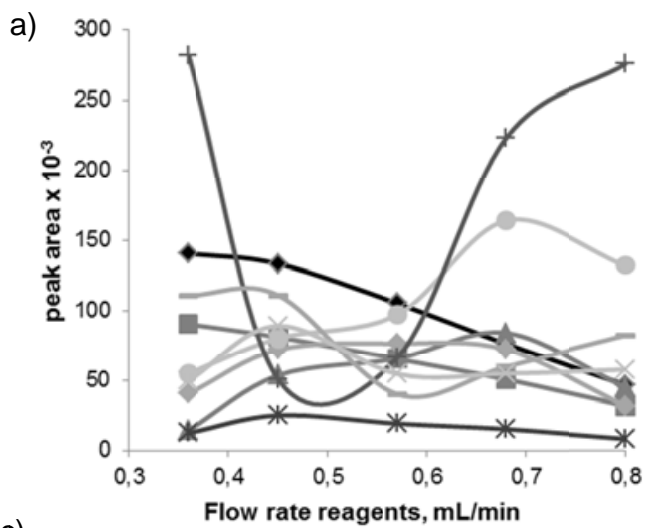

c)

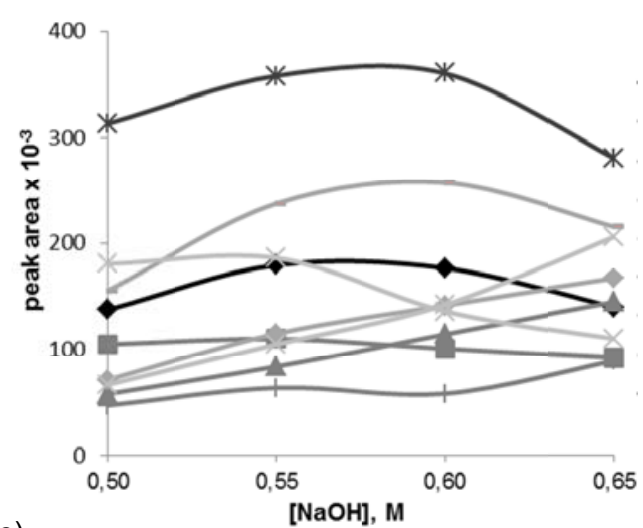

e)

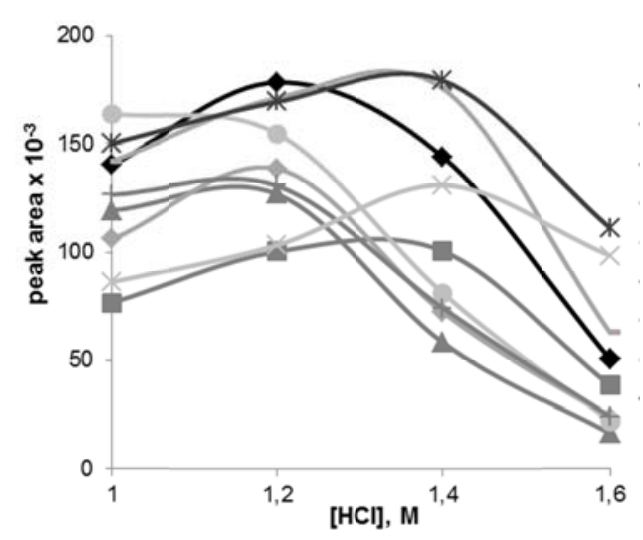

b)

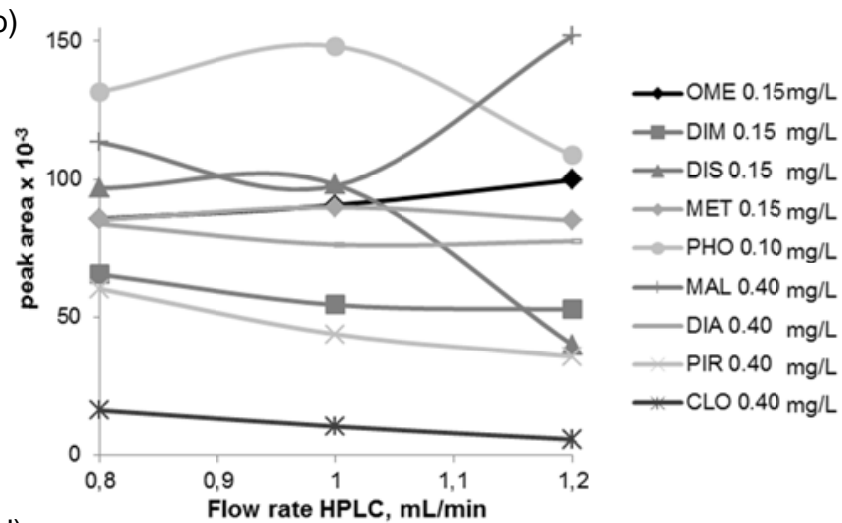

d)

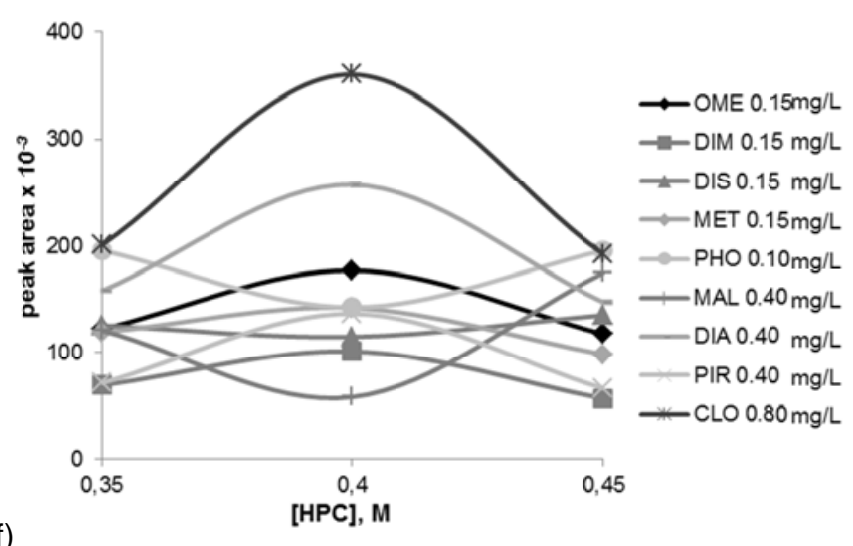

f)

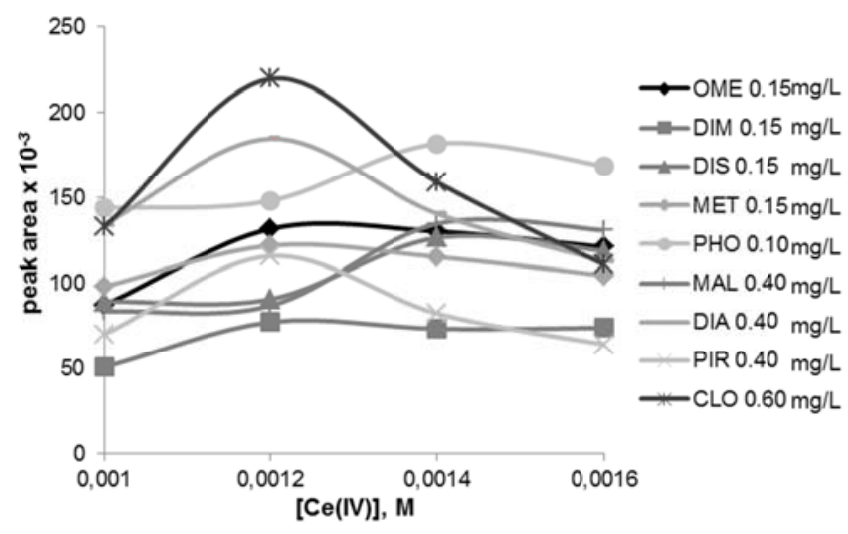

Figure 2. Influence of the flow rates and concentration of CL reactants on the analytical CL signal, for the selected OTP pesticides.

The influence of $\mathrm{NaOH}$ concentration in the hydrolysis step was studied over the range 0.50 - 0.65 M, as shown in Fig. 2c. Most of the OTP pesticides presented maximum values at 0.55 or $0.60 \mathrm{M}$ of $\mathrm{NaOH}$ and emissions decreased in intensity at higher concentrations, probably due to the formation of different chemical species on CL. However, for PHO, MET, DIS and MAL, the signal rose when concentrations were increased in the whole range studied. A value of $0.6 \mathrm{M}$ for $\mathrm{NaOH}$ concentration was selected. 
Surfactants could often protect excited species from interaction with other molecules in the solution, thus favouring CL emission [8]. In our system, the effect of the HPC surfactant concentration on the CL was fairly uniform, since most of the pesticides showed maximum values with an HPC concentration of $0.4 \%$, with the exception of MAL, PHO and DIS (see Fig. 2d). Consequently, this value was selected for further work.

The $\mathrm{HCl}$ concentration employed as the oxidation medium was studied in the interval 1.0 to 1.6 M, as shown in Fig. 2e. A concentration of $1.2 \mathrm{M}$ was selected since at this value most of the pesticides showed maximum emission signals.

In order to study the effect of Ce(IV) concentration on the CL signal, values in the range 1.0 $10^{-3}-1.610^{-3} \mathrm{M}$ were investigated, as shown in Fig. $2 \mathrm{f}$. Maximum signals were found at around $1.210^{-3}$ and $1.410^{-3} \mathrm{M}$, with $1.310^{-3} \mathrm{M}$ being the concentration selected for further work.

The effect of variations in temperature on CL signals was also explored by varying the temperature of the flow cell in the luminometer. Values between room temperature and $50^{\circ} \mathrm{C}$ were assayed, but no differences were found for any of the OTP pesticides. Thus, room temperature was selected for further work.

Finally, the percentage of organic solvent (ACN) in the injected solution was studied over the range 20 - 100\% (OTP concentration: $0.4 \mathrm{mg} / \mathrm{L}$ for MAL, DIA, PIR and CLO and 0.15 mg/L for other pesticides). Percentages above $40 \%$ affected the peak shape negatively. Although $40 \%$ of ACN slightly inhibited the DIM signal, this value was selected in order to avoid solubility problems.

The retention times of OTP compounds for the HPLC-DAD and HPLC-CL systems in optimal conditions are shown in Table 1. 
Table 1. Molecular structures and retention times $\left(t_{R}\right)$ of the selected pesticides in DAD and CL detection systems.

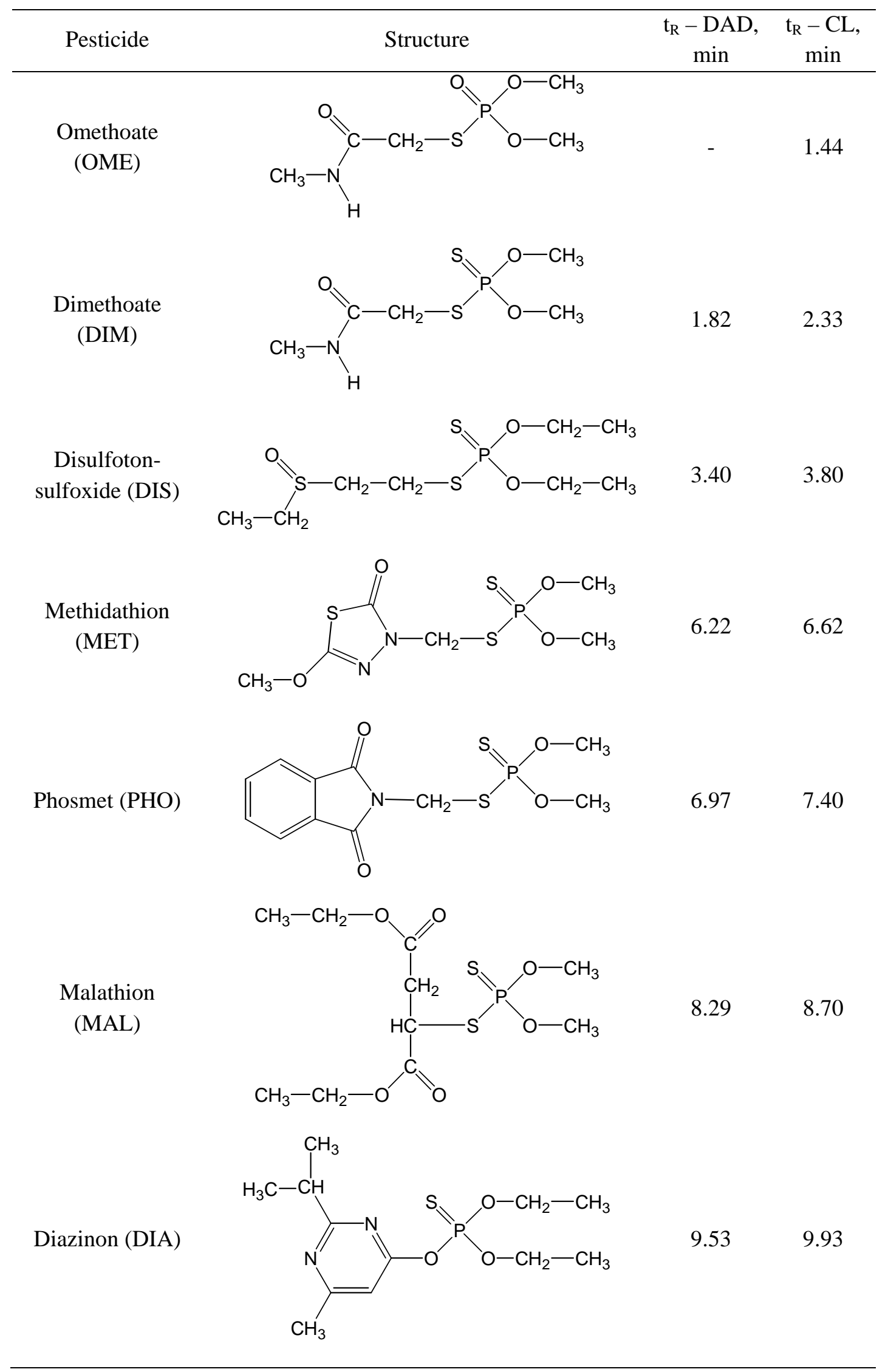




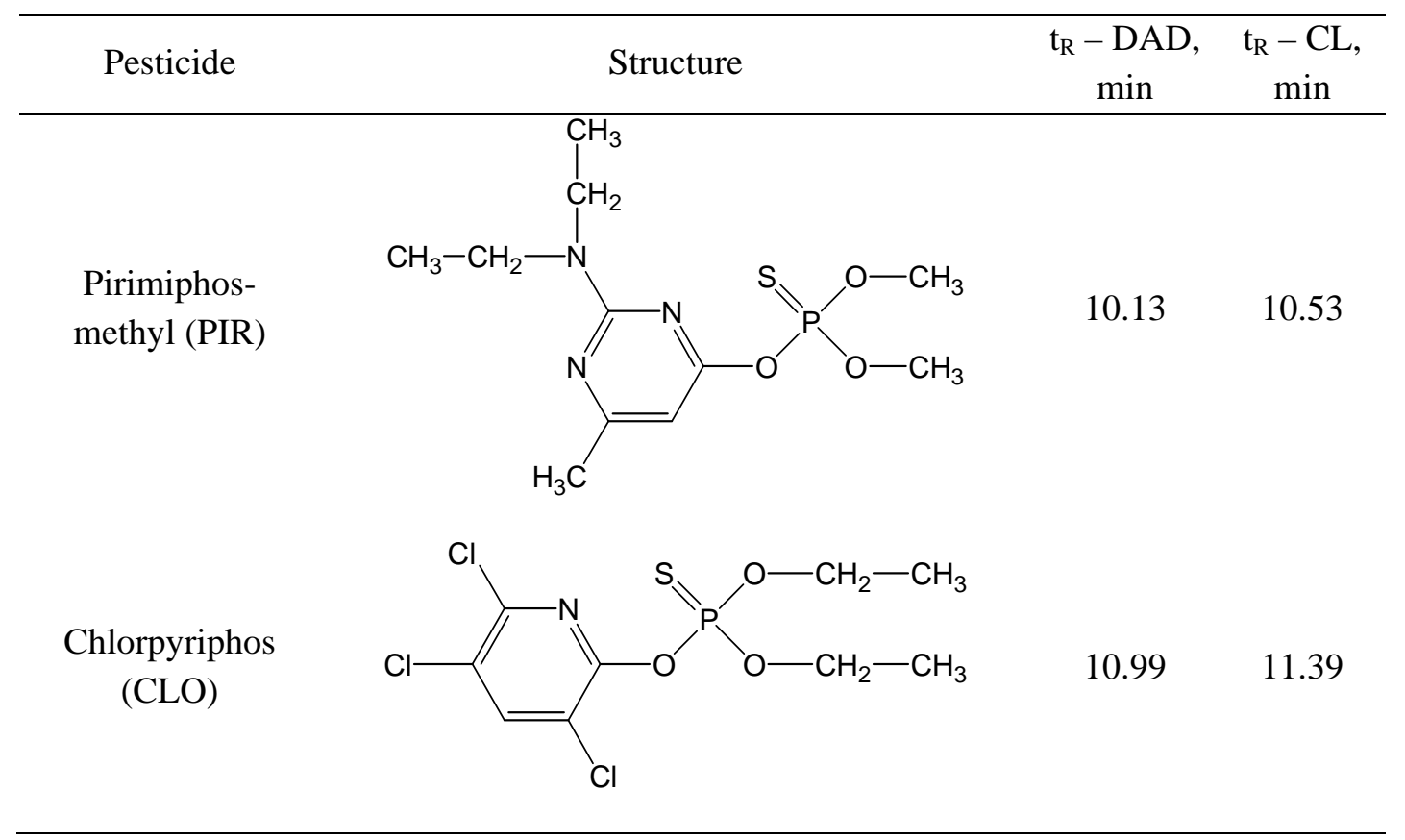

\subsection{Development of the SPE method}

The simultaneous extraction of OPP compounds with a broad range of polarity from water samples is difficult [21]. Although a wide variety of extraction methods has been proposed for OPPs pesticides, SPE is the most popular [6,7]. Two different cartridges for SPE were considered in the present study: Bond Elut-C18 and Strata-X.

In order to compare both cartridges, $250 \mathrm{~mL}$ of standard solutions with concentrations of 0.8 and $1.6 \mu \mathrm{g} / \mathrm{L}$ of each pesticide (1.4 and $2.8 \mu \mathrm{g} / \mathrm{L}$ for MAL and PIR) were treated as described in section 2.4. Three replicates of each concentration were prepared.

With C18 cartridges OME and PIR were not recovered at all, and only around 60\% of CLO and DIM were recovered. On the other hand, Strata-X cartridges allowed the recovery of all the pesticides, although not completely in the case of OME, a very polar pesticide, and CLO, which was strongly retained due its hydrophobic character. Strata-X cartridges were thus selected for extraction.

In order to confirm the results, and to ascertain the behaviour of Strata-X cartridges at different concentrations, calibration curves with 8 standard solution concentrations of the pesticides were prepared, covering, after pre-concentration, the whole linear interval found for each pesticide (see Table 2). Volumes of 250 and $1000 \mathrm{~mL}$ of standard solution were used in order to obtain a 50 and 200-fold pre-concentration factor, respectively. In general, good recoveries were found, with mean values between $92.3 \%$ and $104.7 \%$. Only CLO and OME gave worse results. Mean recovery for CLO was $58 \%$ and $61 \%$ for 250 and $1000 \mathrm{~mL}$ of solution, respectively. An increase in the elution 
volume of ACN up to $4 \mathrm{~mL}$ did not increase recovery. For OME, mean recoveries were $69.7 \%$ and $42.9 \%$ for 250 and $1000 \mathrm{~mL}$, respectively. The results for OME agree with those previously reported [22] because this pesticide presents a high polarity and it is extremely soluble in water; thus, it cannot be effectively extracted from water with most of the conventional sorbents. 
Table 2. Analytical figures of merit of the HPLC-CL method.

\begin{tabular}{|c|c|c|c|c|c|c|c|c|c|c|c|c|c|c|}
\hline \multirow[b]{2}{*}{ Pest. } & \multicolumn{6}{|c|}{ Without SPE } & \multicolumn{5}{|c|}{$250 \mathrm{~mL} \mathrm{SPE}$} & \multicolumn{3}{|c|}{$1000 \mathrm{~mL} \mathrm{SPE}$} \\
\hline & $\begin{array}{c}\text { Linear } \\
\text { range, } \\
\mu g / L\end{array}$ & $\begin{array}{l}\text { Instrumental } \\
\text { precision }\end{array}$ & $\begin{array}{l}\text { LOD, } \\
\mu \mathrm{g} / \mathrm{L}\end{array}$ & $\begin{array}{l}\mathrm{LOQ}, \\
\mu \mathrm{g} / \mathrm{L}\end{array}$ & $\begin{array}{c}\text { LOD, } \\
\mu \mathrm{g} / \mathrm{L} \\
\mathrm{DAD}^{\mathrm{b}}\end{array}$ & $\begin{array}{c}\text { LOQ, } \\
\mu \mathrm{g} / \mathrm{L} \\
\mathrm{DAD}^{\mathrm{b}}\end{array}$ & $\begin{array}{c}\text { Linear } \\
\text { range, } \\
\mu g / L\end{array}$ & $\begin{array}{l}\text { Inter-day } \\
\text { precision, } \\
\%(n=5)^{\mathrm{a}}\end{array}$ & $\begin{array}{l}\text { Intra-day } \\
\text { precision, } \\
\%(n=7)^{\mathrm{a}}\end{array}$ & $\begin{array}{l}\text { LOD, } \\
\mathrm{ng} / \mathrm{L}\end{array}$ & $\begin{array}{l}\text { LOQ, } \\
\text { ng/L }\end{array}$ & $\begin{array}{c}\text { Linear } \\
\text { range, } \\
\mu \mathrm{g} / \mathrm{L}\end{array}$ & $\begin{array}{l}\text { LOD, } \\
\text { ng/L }\end{array}$ & $\begin{array}{c}\mathrm{LOQ}, \\
\mathrm{ng} / \mathrm{L}\end{array}$ \\
\hline OME & $6-100$ & 3.4 & 1.8 & 6 & - & - & $0.12-2$ & 4.1 & 3.0 & 80 & 300 & $0.03-0.5$ & 30 & 100 \\
\hline DIM & $20-150$ & 4.3 & 6 & 20 & - & - & $0.4-3$ & 7.3 & 5.6 & 80 & 300 & $0.1-0.75$ & 25 & 85 \\
\hline DIS & $4-100$ & 6.7 & 1.2 & 4 & 6.5 & 22 & $0.08-2$ & 5.8 & 3.7 & 25 & 100 & $0.02-0.5$ & 6 & 20 \\
\hline MET & 4-100 & 3.6 & 1.2 & 4 & 7.2 & 24 & $0.08-2$ & 6.1 & 3.8 & 25 & 100 & $0.02-0.5$ & 6 & 20 \\
\hline MAL & $10-300$ & 4.5 & 3 & 10 & 8 & 27 & $0.2-6$ & 6.8 & 6.0 & 55 & 200 & $0.05-1.5$ & 15 & 50 \\
\hline DIA & $4-100$ & 5.5 & 1.2 & 4 & 3.7 & 12 & $0.08-2$ & 3.5 & 2.9 & 30 & 100 & $0.02-0.5$ & 6 & 20 \\
\hline PIR & $10-300$ & 5.8 & 3 & 10 & 2 & 7 & $0.2-6$ & 5.9 & 3.4 & 70 & 200 & $0.05-1.5$ & 20 & 65 \\
\hline CLO & 4-100 & 2.9 & 1.2 & 4 & 1.2 & 4 & $0.08-2$ & 4.9 & 3.7 & 50 & 200 & $0.02-0.5$ & 10 & 35 \\
\hline
\end{tabular}

${ }^{\mathrm{a}}$ Concentration of pesticide: $1.5 \mu \mathrm{g} / \mathrm{L}$ for DIM and MAL, $2 \mu \mathrm{g} / \mathrm{L}$ for PIR and MAL, and $1 \mu \mathrm{g} / \mathrm{L}$ for the other OTP pesticides.

${ }^{\mathrm{b}}$ Data for the HPLC-DAD method. 


\subsection{Analytical characteristics}

The linear range and relative standard deviation (RSD) of the slope of five calibration curves (instrumental precision), obtained with this HPLC-CL method without pre-concentration, are summarized in Table 2. The correlation coefficients (r) obtained with these calibration graphs were over 0.992 in all cases.

With the HPLC-CL method without preconcentration, LODs were between 0.8 and $6 \mu \mathrm{g} / \mathrm{L}$. They were therefore between 2.7 and 6 times lower than those obtained with DAD detection (Table 2). Only PIR and CLO gave similar LODs and LOQs with both detection systems. Although greater sensitivity of CL versus DAD determination was expected [9], it should be noted that the optimization process must find a compromise between the CL response for all the pesticides tested. Accordingly, the greater sensitivity value of one is often disregarded in order to have the best results for the whole group.

It is worth pointing out that DAD applicability was more limited, since it was not possible to determine OME and DIM. The OME peak completely overlapped with the eluent front in the DAD chromatogram, while DIM signals were very small in the interval of concentrations employed for CL determination and slightly overlapped with the eluent front.

The potential interference of cypermethrin in the proposed method was evaluated because this pesticide is formulated together with CLO in some commercial preparations [23]. Therefore, cypermethrin was injected into the HPLC-CL system, and it was found that it did not exhibit CL response. Moreover, its retention time was 11.6 min (determined with the DAD detector), which did not overlap with any of the nine OTP pesticides.

With the SPE-HPLC-CL system, the LODs and LOQs with standard solution for volumes of $250 \mathrm{~mL}$ and $1000 \mathrm{~mL}$ were also determined. Table 2 shows the results obtained: nine OTP pesticides were detected at concentrations in the range of 15-80 ng/L and 5-30 ng/L for 250 and $1000 \mathrm{~mL}$, respectively. These LODs are below the maximum residue limit of $0.1 \mu \mathrm{g} / \mathrm{L}$ for individual pesticides in drinking water allowed by the European Drinking Water Directive [24]. However, to monitor the limit value of $0.1 \mu \mathrm{g} / \mathrm{L}$, a LOD of at least $0.025 \mu \mathrm{g} / \mathrm{L}$ is required. This value can be achieved when 1 $\mathrm{L}$ of sample is processed (except for OME). Figure 3 shows the chromatograms for a standard solution of $0.1 \mu \mathrm{g} / \mathrm{L}$ obtained after processing $250 \mathrm{~mL}$ and $1000 \mathrm{~mL}$, and another corresponding to $0.025 \mu \mathrm{g} / \mathrm{L}$ in a volume of $1000 \mathrm{~mL}$. 

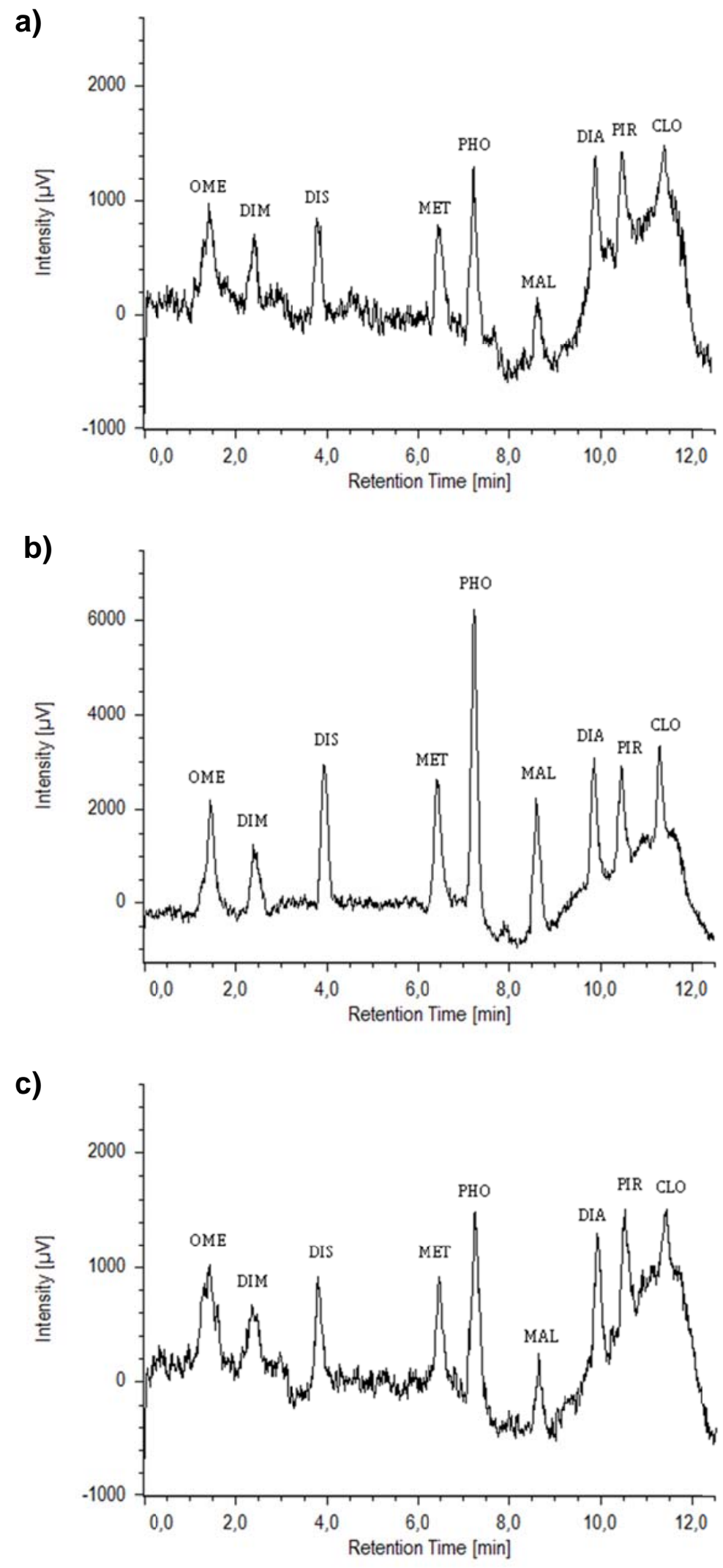

Figure 3. SPE-HPLC-CL chromatograms of standard solution of the nine pesticides at: a) $0.1 \mu \mathrm{g} / \mathrm{L}$ when $250 \mathrm{~mL}$ are treated; b) $0.1 \mu \mathrm{g} / \mathrm{L}$ when $1 \mathrm{~L}$ is treated; c) $0.025 \mu \mathrm{g} / \mathrm{L}$ when $1 \mathrm{~L}$ is treated. 
The intra-day precision was between $2.9 \%$ and $6.0 \%$, while the inter-day precision was between $3.5 \%$ and $7.3 \%$. These values show that the method, including the SPE step, is very reproducible.

\subsection{Application to water samples and validation}

Finally, the proposed SPE-HPLC-CL method was applied to the determination of the OTP pesticides in $250 \mathrm{~mL}$ of water samples from seven different sources.

No OTP was detected when a blank sample was analysed using the proposed method. The CL chromatogram from all blank samples was very clean since only a peak with a short retention time (about $1.3 \mathrm{~min}$ ) was obtained and its intensity depended on the matrix. However, it was not possible to assign this peak to OME (retention time $1.44 \mathrm{~min}$ ) since it completely overlapped with the eluent front in the DAD spectra. This peak made it impossible to quantify OME in the water samples tested. Fig. 4 shows a CL chromatogram of an irrigation water sample spiked with the OTP pesticides mixture (black line) and the blank chromatogram (grey line). The blank obtained with this sample, which had a very complex matrix, presented another small peak at $11.6 \mathrm{~min}$, slightly overlapping with CLO, and not found in other samples. Moreover, when DAD detection was employed, many peaks were found in the blank sample (Appendix A), some of them overlapping with OTP peaks. In addition, these peaks were often so high that the results could not be reproduced or it was impossible to determine the pesticides. Thus, the selectivity of CL was better than DAD detection.

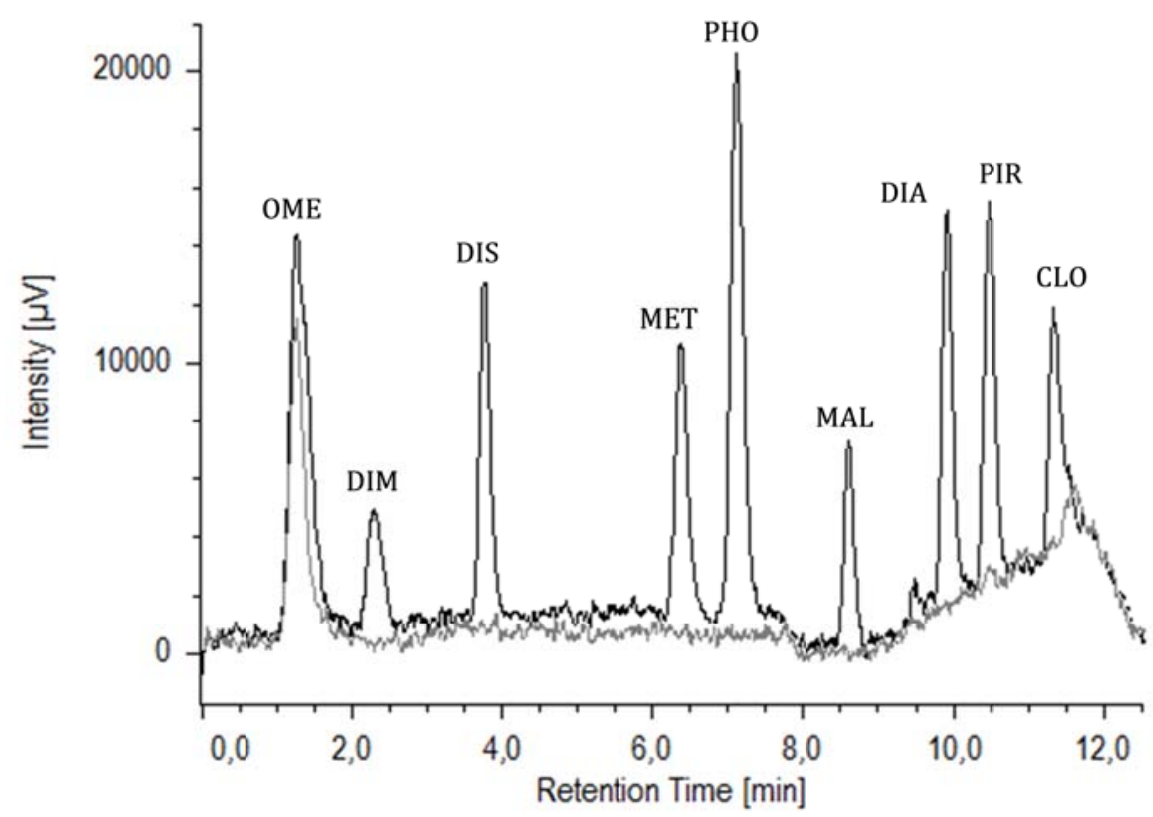

Figure 4. SPE(250 mL)-HPLC-CL chromatograms of an irrigation water sample (black line) spiked with 0.7 $\mu \mathrm{g} / \mathrm{L}$ of OME, DIS, MET, DIA and CLO, $0.6 \mu \mathrm{g} / \mathrm{L}$ of PHO, $0.8 \mu \mathrm{g} / \mathrm{L}$ of DIM and $1.4 \mu \mathrm{g} / \mathrm{L}$ of MAL and PIR; and the corresponding blank (grey line) 
As has been described in section 2.5, samples were spiked with the mixture of OTPs at two different levels, and three replicates of each level were prepared. The results are shown in Table 3. Recoveries versus added amount and versus result obtained by the SPE-HPLC-DAD system were estimated. The former was influenced by the global process SPE-HPLC-CL, whereas those obtained by comparison with DAD determination showed only the error associated with the detection method (CL versus DAD). In general, very good results were obtained, bearing in mind that the acceptable range for recoveries in water samples is usually set between $70 \%$ and $110 \%$, with a maximum permitted RSD of 20\% [25]. Therefore, the analytical performance of the proposed method was successful. The low recoveries from CLO when compared with the added amount are mainly related with losses in the extraction step and not with errors in CL determination, as shown by the good rates of recovery obtained when compared with DAD results.

On the other hand, recoveries for PHO and MAL were generally somewhat worse when compared with the added amount (PHO - excessively low; MAL - excessively high) in several samples. This is because these pesticides are less stable in aqueous solution [26]. This explanation is supported by the results of DAD detection in the case of PHO (MAL could only be determined with DAD in tap water). 
Table 3. Analysis of spiked water samples with the SPE-HPLC-CL method (mean of three determinations).

\begin{tabular}{|c|c|c|c|c|c|c|c|c|c|c|c|}
\hline Sample & Pesticide & $\begin{array}{l}\text { Added, } \\
\mu \mathrm{g} / \mathrm{L}\end{array}$ & $\begin{array}{l}\text { Found } \\
\text { CL, } \\
\mu \mathrm{g} / \mathrm{L}\end{array}$ & $\begin{array}{l}\text { \% Recovery } \\
\text { CL vs added } \\
\text { (RSD, \%) }\end{array}$ & $\begin{array}{l}\text { Found } \\
\text { DAD, } \\
\mu \mathrm{g} / \mathrm{L}\end{array}$ & $\begin{array}{l}\text { \% Recovery } \\
\text { CL vs DAD } \\
\text { (RSD, \%) }\end{array}$ & $\begin{array}{l}\text { Added, } \\
\mu \mathrm{g} / \mathrm{L}\end{array}$ & $\begin{array}{l}\text { Found } \\
\text { CL, } \\
\mu \mathrm{g} / \mathrm{L}\end{array}$ & $\begin{array}{l}\text { \% Recovery } \\
\text { CL vs added } \\
\text { (RSD, \%) }\end{array}$ & $\begin{array}{l}\text { Found } \\
\text { DAD, } \\
\mu \mathrm{g} / \mathrm{L}\end{array}$ & $\begin{array}{c}\text { \% Recovery } \\
\text { CL vs DAD } \\
\text { (RSD, \%) }\end{array}$ \\
\hline \multirow[t]{8}{*}{ Tap } & DIM & 0.8 & 0.84 & $105.2(6.2)$ & - & - & 1.6 & 1.54 & $96.4(5.2)$ & - & - \\
\hline & DIS & 0.7 & 0.83 & $119.2(3.4)$ & 0.82 & $101.6(5.8)$ & 1.4 & 1.39 & 99.5 (7.5) & 1.44 & $96.8(10.0)$ \\
\hline & MET & 0.7 & 0.70 & $106.1(2.3)$ & 0.71 & 104.4 (2.9) & 1.4 & 1.42 & $101.5(4.4)$ & 1.39 & $102.2(4.6)$ \\
\hline & $\mathrm{PHO}$ & 0.6 & 0.55 & 92.4 (8.9) & 0.60 & 92.3 (8.9) & 1.2 & 1.53 & $109.1(5.1)$ & 1.37 & $111.3(5.2)$ \\
\hline & MAL & 1.4 & 1.29 & 85.4 (1.6) & 1.20 & $-\mathrm{a}$ & 2.8 & 3.27 & $116.8(6.7)$ & 3.08 & $-{ }^{a}$ \\
\hline & DIA & 0.7 & 0.70 & 99.7 (6.8) & 0.72 & 97.5 (8.1) & 1.4 & 1.39 & $99.4(4.6)$ & 1.42 & 98.2 (8.1) \\
\hline & PIR & 1.4 & 1.28 & 99.7 (6.8) & 1.24 & $90.4(5.8)$ & 2.8 & 2.75 & $98.2(4.0)$ & 2.75 & $100.1(8.4)$ \\
\hline & CLO & 0.7 & 0.33 & $47.3(6.2)$ & 0.36 & 91.9 (6.3) & 1.4 & 0.75 & 53.5 (6.8) & 0.81 & $92.0(7.4)$ \\
\hline \multirow[t]{8}{*}{ Ground } & DIM & 0.8 & 0.81 & $100.8(6.5)$ & - & - & 1.6 & 1.54 & $96.0(7.5)$ & - & - \\
\hline & DIS & 0.7 & 0.68 & 96.5 (4.3) & 0.67 & 100.2 (11.1) & 1.4 & 1.36 & $96.9(3.0)$ & 1.32 & $103.1(4.6)$ \\
\hline & MET & 0.7 & 0.64 & $92.1(7.2)$ & 0.69 & $93.5(7.7)$ & 1.4 & 1.42 & $101.2(4.6)$ & 1.43 & $99.1(5.1)$ \\
\hline & $\mathrm{PHO}$ & 0.6 & 0.53 & $89.0(1.7)$ & 0.52 & $102.8(2.5)$ & 1.2 & 1.02 & $84.7(1.2)$ & 1.04 & 98.0 (1.3) \\
\hline & MAL & 1.4 & 1.39 & $99.0(4.8)$ & - & $-{ }^{a}$ & 2.8 & 3.27 & $116.8(11.0)$ & - & $-{ }^{a}$ \\
\hline & DIA & 0.7 & 0.73 & $103.9(5.8)$ & 0.73 & $100.4(6.8)$ & 1.4 & 1.28 & $91.8(4.5)$ & 1.32 & $97.5(11.1)$ \\
\hline & PIR & 1.4 & 1.39 & $99.4(6.2)$ & 1.45 & $95.7(6.6)$ & 2.8 & 2.56 & $91.4(9.1)$ & 2.69 & $95.0(9.2)$ \\
\hline & CLO & 0.7 & 0.31 & 44.9 (3.2) & 0.29 & $109.0(9.8)$ & 1.4 & 0.69 & 49.0 (9.3) & 0.64 & 107.5 (11.5) \\
\hline \multirow[t]{8}{*}{ Spring } & DIM & 0.8 & 0.77 & $96.8(5.8)$ & - & - & 1.6 & 1.62 & $101.4(2.0)$ & - & - \\
\hline & DIS & 0.7 & 0.76 & $108.5(1.8)$ & 0.72 & $105.5(4.7)$ & 1.4 & 1.35 & $96.4(1.5)$ & 1.40 & 96.2 (1.9) \\
\hline & MET & 0.7 & 0.70 & $99.8(1.8)$ & 0.69 & $101.3(6.7)$ & 1.4 & 1.30 & $93.1(1.2)$ & 1.45 & $89.8(2.0)$ \\
\hline & $\mathrm{PHO}$ & 0.6 & 0.53 & 88.3 (1.7) & 0.48 & 110.0 (1.9) & 1.2 & 0.97 & 80.9 (5.8) & 0.94 & $103.4(5.8)$ \\
\hline & MAL & 1.4 & 1.51 & $107.7(6.2)$ & - & $-{ }^{a}$ & 2.8 & 3.09 & $110.3(1.8)$ & - & $-{ }^{a}$ \\
\hline & DIA & 0.7 & 0.68 & $96.7(1.5)$ & - & $-{ }^{a}$ & 1.4 & 1.37 & $97.8(1.0)$ & - & $-{ }^{a}$ \\
\hline & PIR & 1.4 & 1.30 & $92.9(3.0)$ & 1.38 & $93.9(6.4)$ & 2.8 & 2.53 & 90.5 (1.9) & 2.70 & $93.8(2.0)$ \\
\hline & CLO & 0.7 & 0.40 & $57.3(1.8)$ & 0.39 & $103.8(8.9)$ & 1.4 & 0.68 & $48.3(12.6)$ & 0.75 & $90.1(13.9)$ \\
\hline \multirow[t]{8}{*}{ Mineral } & DIM & 0.8 & 0.87 & $108.4(4.1)$ & - & - & 1.6 & 1.63 & $102.1(7.4)$ & - & - \\
\hline & DIS & 0.7 & 0.73 & $104.5(8.4)$ & 0.67 & $109.9(8.6)$ & 1.4 & 1.22 & $87.0(3.5)$ & 1.29 & 94.1 (3.9) \\
\hline & MET & 0.7 & 0.65 & $92.6(2.6)$ & 0.60 & $107.8(7.7)$ & 1.4 & 1.06 & 75.4 (7.9) & 1.14 & 92.7 (7.8) \\
\hline & $\mathrm{PHO}$ & 0.6 & 0.44 & $72.8(8.7)$ & 0.41 & $107.5(8.8)$ & 1.2 & 0.91 & $75.8(6.2)$ & 0.83 & $109.0(7.0)$ \\
\hline & MAL & 1.4 & 1.67 & $119.5(4.1)$ & - & $-{ }^{a}$ & 2.8 & 3.26 & $116.3(10.5)$ & - & $-{ }^{a}$ \\
\hline & DIA & 0.7 & 0.68 & $97.3(5.0)$ & 0.64 & $107.1(13.7)^{\mathrm{a}}$ & 1.4 & 1.09 & $80.8(1.1)$ & 1.05 & $103.8(6.9)$ \\
\hline & PIR & 1.4 & 1.15 & $82.1(8.7)$ & 1.16 & $98.8(8.9)$ & 2.8 & 2.39 & $85.5(7.0)$ & 2.42 & 99.0 (7.9) \\
\hline & CLO & 0.7 & 0.28 & $40.4(10.0)$ & 0.30 & $97.3(21.2)^{\mathrm{a}}$ & 1.4 & 0.61 & $46.2(6.0)$ & 0.62 & $98.0(19.6)^{a}$ \\
\hline \multirow[t]{8}{*}{ River } & DIM & 0.8 & 0.82 & $102.6(2.3)$ & - & - & 1.6 & 1.54 & $96.3(2.9)$ & - & - \\
\hline & DIS & 0.7 & 0.74 & $105.6(2.0)$ & 0.71 & $104.3(3.5)$ & 1.4 & 1.41 & $100.5(0.7)$ & 1.37 & $102.4(1.5)$ \\
\hline & MET & 0.7 & 0.72 & 102.9 (4.9) & 0.71 & $101.5(5.5)$ & 1.4 & 1.47 & $105.1(4.8)$ & 1.35 & $109.1(6.3)$ \\
\hline & $\mathrm{PHO}$ & 0.6 & 0.41 & $68.2(3.1)$ & 0.34 & $119.6(8.5)$ & 1.2 & 0.83 & $68.8(0.8)$ & 0.67 & $123.5(5.6)$ \\
\hline & MAL & 1.4 & 1.47 & $105.1(1.6)$ & - & $-{ }^{a}$ & 2.8 & 2.70 & 96.4 (3.4) & - & $-{ }^{a}$ \\
\hline & DIA & 0.7 & 0.69 & $98.7(6.2)$ & - & $-{ }^{a}$ & 1.4 & 1.31 & 93.5 (3.3) & - & $-{ }^{a}$ \\
\hline & PIR & 1.4 & 1.01 & $71.2(6.6)$ & 1.09 & $91.6(7.7)$ & 2.8 & 2.59 & $92.5(4.8)$ & 2.46 & $105.3(4.8)$ \\
\hline & CLO & 0.7 & 0.57 & $81.7(2.5)$ & 0.52 & $109.0(4.4)$ & 1.4 & 1.01 & $72.0(1.5)$ & 0.83 & $121.5(2.7)$ \\
\hline \multirow[t]{8}{*}{ Sea } & DIM & 0.8 & 0.73 & 90.7 (8.6) & - & - & 1.6 & 1.36 & $85.2(6.7)$ & - & - \\
\hline & DIS & 0.7 & 0.75 & 106.5 (1.1) & 0.72 & $104.0(7.8)$ & 1.4 & 0.75 & 106.5 (1.1) & 0.72 & $104.0(7.8)$ \\
\hline & MET & 0.7 & 0.68 & $97.7(6.7)$ & 0.66 & $104.1(10.4)$ & 1.4 & 1.19 & $84.8(9.8)$ & 1.23 & $96.6(9.9)$ \\
\hline & $\mathrm{PHO}$ & 0.6 & 0.41 & $68.6(8.8)$ & 0.38 & $107.2(10.4)$ & 1.2 & 0.95 & $79.4(7.3)$ & 0.86 & $110.9(8.0)$ \\
\hline & MAL & 1.4 & 1.52 & 108.9 (3.1) & - & $-{ }^{a}$ & 2.8 & 3.07 & $109.6(7.8)$ & - & $-{ }^{a}$ \\
\hline & DIA & 0.7 & 0.63 & $90.0(5.0)$ & 0.61 & $103.9(6.0)$ & 1.4 & 1.37 & $97.9(4.3)$ & - & $-a$ \\
\hline & PIR & 1.4 & 1.35 & $96.1(4.5)$ & 1.36 & $98.9(6.9)$ & 2.8 & 2.73 & $97.5(8.5)$ & 2.65 & $102.9(8.5)$ \\
\hline & CLO & 0.7 & 0.41 & $58.4(8.8)$ & 0.43 & $94.7(23.9)^{\mathrm{a}}$ & 1.4 & 0.63 & $45.0(10.2)$ & 0.68 & $92.3(14.3)^{\mathrm{a}}$ \\
\hline \multirow[t]{8}{*}{ Irrigation } & DIM & 0.8 & 0.79 & $99.3(6.3)$ & - & - & 1.6 & 1.61 & $100.5(2.7)$ & - & - \\
\hline & DIS & 0.7 & 0.76 & $108.2(4.8)$ & 0.74 & $98.3(8.0)$ & 1.4 & 1.49 & $106.2(3.5)$ & 1.42 & $95.6(4.2)$ \\
\hline & MET & 0.7 & 0.70 & $100.0(5.6)$ & 0.66 & 94.8 (6.9) & 1.4 & 1.42 & $101.6(2.3)$ & 1.38 & $97.3(4.0)$ \\
\hline & $\mathrm{PHO}$ & 0.6 & 0.45 & $74.9(7.4)$ & 0.43 & 95.1 (7.5) & 1.2 & 1.00 & $83.0(3.4)$ & 0.91 & 91.6 (3.7) \\
\hline & MAL & 1.4 & 1.35 & $96.1(0.7)$ & - & $-{ }^{a}$ & 2.8 & 3.10 & $110.9(5.1)$ & - & $-{ }^{a}$ \\
\hline & DIA & 0.7 & 0.68 & $96.7(9.0)$ & 0.63 & $93.2(20.9)^{\mathrm{a}}$ & 1.4 & 1.38 & $98.7(4.4)$ & 1.35 & 98.1 (4.9) \\
\hline & PIR & 1.4 & 1.28 & 91.1 (7.9) & 1.40 & $109.6(9.8)$ & 2.8 & 2.89 & 103.3 (3.5) & 2.89 & 100.0 (3.6) \\
\hline & CLO & 0.7 & 0.41 & 59.0 (3.8) & 0.42 & $101.0(4.0)$ & 1.4 & 0.85 & $57.3(5.8)$ & 0.85 & $106.5(7.0)$ \\
\hline
\end{tabular}

${ }^{\mathrm{a}}$ A valuable blank peak, overlapping with the pesticide, made impossible the determination or increased the RSD. 


\subsection{Comparison with related methods}

In Table 4, LODs from FIA-CL and HPLC-CL methods developed for pesticide determination are compared with our results. As has been shown in Section 3.4 above, the LODs without SPE of the OTP pesticides included in our research were between 0.8 and $6.0 \mu \mathrm{g} / \mathrm{L}$, and between 0.015 and $0.08 \mu \mathrm{g} / \mathrm{L}$ or 0.005 and $0.03 \mu \mathrm{g} / \mathrm{L}$ for 250 or $1000 \mathrm{~mL}$ of sample concentrated by SPE, respectively.

Table 4. Comparison of LODs with related methods.

\begin{tabular}{|c|c|c|}
\hline Methods and compounds & LODs, $\mu \mathrm{g} / \mathrm{L}$ & References \\
\hline \multicolumn{3}{|l|}{ FIA-CL OPP with strong oxidants } \\
\hline Buminafos & 5 & [27] \\
\hline DIA, MAL & 100,300 & [28] \\
\hline DIM & 0.05 & [13] \\
\hline Fenamifos & 10 & {$[14]$} \\
\hline \multicolumn{3}{|l|}{ FIA-CL OPP with luminol } \\
\hline CLOene & 0.18 & [29] \\
\hline Diclorvos & 8 & {$[30]$} \\
\hline Diclorvos, OME, thichlorfon & 10 & [31] \\
\hline Fenitrothion, & 4 & [32] \\
\hline Methamidophos & 47 & [33] \\
\hline Monocrotophos & 7 & [34] \\
\hline Parathion, parathion-methyl & 8,20 & [35] \\
\hline Paraoxon & 10 & {$[36]$} \\
\hline Phosphamidon & 3.8 & {$[4]$} \\
\hline Phosphamidon & 18 & [37] \\
\hline Phoxim & 5.4 & {$[10]$} \\
\hline \multicolumn{3}{|l|}{ FIA-CL OPP with $R u(b p y)_{3}{ }^{2+}$} \\
\hline Glyphosate & 1.18 & [38] \\
\hline \multicolumn{3}{|l|}{ HPLC-CL OPP with luminol } \\
\hline $\begin{array}{l}\text { HPLC-CL OPP with Ru(bpy) }{ }_{3}{ }^{2+} \\
\text { Glyphosate and related compounds }\end{array}$ & 20 & [39] \\
\hline \multicolumn{3}{|l|}{ HPLC-CL other pesticides with strong-oxidants } \\
\hline OTP present work & $0.8-6.0$ & - \\
\hline Pyrethroids & $13-49$ & [18] \\
\hline
\end{tabular}

LODs of the FIA-CL methods developed for OPP determination were higher except in two cases: for DIM (0.05 $\mu \mathrm{g} / \mathrm{L}$, with strong oxidants [13]) and CLO (0.18 $\mu \mathrm{g} / \mathrm{L}$, with luminol [29]).

The LODs of HPLC-CL methods for OPP determination, based on luminol [12] or tris(2,2' bipyridine)ruthenium(II) $\left(\mathrm{Ru}(\mathrm{bpy})_{3}{ }^{2+}\right.$ ) [39] system, were higher than $20 \mu \mathrm{g} / \mathrm{L}$. These values are clearly higher than those obtained in the present study. The LODs found with HPCL-CL methods employing strong oxidants were similar or higher.

On the other hand, comparison of the proposed method with chromatographic-MS shows that the LODs are usually of the same order, as has been reviewed by Tankiewics et al. [7]. 


\section{Conclusions}

A new HPLC-CL method has been developed for the determination of OTP pesticides in water samples. The post-column CL detection was based on the reaction of hydrolyzed pesticides in a basic medium with acidic cerium (IV). HPC acted as a light emission enhancer. The chromatographic separation was performed with a gradient of ACN:water and a C18 stationary phase, allowing the complete resolution of the nine pesticides studied in less than $12 \mathrm{~min}$.

The CL chromatograms presented a low background of the baseline and almost an absence of interfering peaks. Consequently, the method developed showed great selectivity; higher than that achieved by HPLC-DAD determination. Also the sensitivity was better and, in combination with the SPE with Strata-X cartridges, allowed the detection of the OTP pesticides at concentrations below the maximum residue limit in drinking water set by the European Drinking Water Directive [24].

\section{References}

[1] C. Barata, A. Solayan, C. Porte, Aquat. Toxicol. 66 (2004) 125.

[2] R. Rahimi, M. Abdollahi, Pestic. Biochem. Physiol. 88 (2007) 115.

[3] A. Garrido Frenich, J.L. Martínez Vidal, A.D. Cruz Sicilia, M.J. González Rodríguez, P. Plaza Bolaños, Anal. Chim. Acta 558 (2006) 42.

[4] A.F. Li, X.Y. Liu, J. Kong, H.Y. Hu, L.H. Sun, Z. Qian, J. AOAC Int. 92 (2009) 914.

[5] R.D. Wauchope, T.M. Buttler, A.G. Hornsby, P.W.M. Augustijn-Beckers, J.P. Burt, Rev. Environ. Contam. Toxicol. 123 (1992) 1.

[6] T.A. Samuels, S.O. Obare, in: M. Stoytcheva (Ed), Pesticides in the Modern World - Trends in Pesticides Analysis, InTech, 2011. Chapter 6. Available from: http://cdn.intechopen.com/pdfs/20988/InTechAdvances_in_analytical_methods_for_organoph osphorus_pesticide_detection.pdf (accessed 14.09.2013).

[7] M. Tankiewicz, J. Fenik, M. Biziuk, Trends Anal. Chem. 29 (2010) 1050.

[8] F.J. Lara, A.M. García-Campaña, J.J. Aaron, Anal. Chim. Acta 679 (2010) 17.

[9] L. Gámiz-Gracia, A.M. García-Campaña, J. Soto-Chinchilla, J.F. Huertas-Pérez, A. González-Casado, Trends Anal. Chem. 24 (2005) 927. 
[10] X.Y. Liu, A.F. Li, M. Chen, M.C. Wu, Chinese J. Anal. Chem. 35 (2007) 1809.

[11] A.F. Li, X.Y. Liu, J. Kong, R. Huang, M.C. Wu, Anal. Lett. 41 (2008) 1375.

[12] G. Huang, J. Ouyang, W.R.G. Baeyens, Y. Yang, Ch. Tau, Anal. Chim. Acta 474 (2002) 21.

[13] M. Catalá-Icardo, J.L. López-Paz, C. Choves-Barón, A. Peña-Bádena, Anal. Chim. Acta 710 (2012) 81.

[14] C. Gómez-Benito, S. Meseguer-Lloret, S. Torres-Cartas, Int. J. Environ. Anal. Chem. 93 (2013) 152.

[15] J.L. López-Paz, M. Catalá-Icardo, Anal. Lett. 44 (2011) 146.

[16] T. Pérez-Ruiz, C. Martínez-Lozano, V. Tomás, J. Martín, J. Chromatogr. A 1026 (2004) 57.

[17] S.L. Fan, L.K. Zhang, J.M. Lin, Talanta 68 (2006) 646.

[18] M. Martínez Galera, M.D. Gil García, R. Santiago Valverde, J. Chromatogr. A, 1113 (2006) 191.

[19] L.A. Curie, Pure Appl. Chem. 67 (1995) 1699.

[20] J. Ruzicka, E.H. Hansen, Flow injection Analysis, Wiley, New York, 2nd ed., 1988.

[21] J. Norberg, J. Slobodnik, R.J.J. Vreuls, U.A.Th. Brinkman. Anal. Methods Instrument. 2 (1995) 266.

[22] Q. Li, X. Wang, D. Yuan. J. Environ. Monit. 11 (2009) 439.

[23] Ministerio de Agricultura, Alimentación y Medio Ambiente. http://www.marm.es (accessed 02.10.2012).

[24] Council Directive 98/83/EC of 3 November 1998 on the quality of water intended for human consumption. Off. J. Eur. Union L330/32 (1998).

[25] D.J. Hamilton, Á. Ambrus, R.M. Dieterle, A.S. Felsot, C.A. Harris, P.T. Holland, A. Katayama, N. Kurihara, J. Linders, J. Unsworth, S.S. Wong, Pure Appl. Chem. 75 (2003) 1123.

[26] IPCS International Programme on Chemical Safety. www.inchem.org. (accessed 17.07.2013)

[27] D. López Malo, J. Martínez Calatayud, Talanta 77 (2008) 561.

[28] A. Waseem, M. Yaqoob, A. Nabi, Luminescence 22 (2007) 349.

[29] Z. Song, S. Hou, N. Zhang, J. Agric. Food Chem. 50 (2002) 4468. 
[30] J.N. Wang, C. Zhang, H.X. Wang, F.Z. Yang, X.R. Zhang, Talanta 54 (2001) 1185.

[31] B. Li, Y. He, C. Xu, Talanta 72 (2007) 223.

[32] X.Y. Liu, A.F. Li, C.M. Wu, J.R. Lu, Anal Lett. 40 (2007) 2737.

[33] X.Z. Li, T.T. Guan, C. Zhou, J.Q. Yin, Y.H. Zhang, Chem. Res. Chin. Univ. 22 (2006) 21.

[34] J. Du, X. Liu, J. Lu, Anal. Lett. 36 (2003) 1029.

[35] X. Liu, J. Du, J. Lu, Luminescence 18 (2003) 245.

[36] A.F. Danet, M. Badea, J.L. Marty, H.Y. Aboul Enein, Biopolymers 57 (2000) 37.

[37] X. Hun, L. Cheng. Chemiluminescence flow sensor with immobilized reagent for the determination of phosphamidon pesticide. ISTM/2005: 6th International Symposium on Test and Measurement. Conference Proceedings. 1-9: 3588-3591 (2005).

[38] J.L. Adcock, N.W. Barnett, R.D. Gerardi, C.E. Lenehan, S.W. Lewis, Talanta 64 (2004) 534.

[39] J.S. Ridlen, G.J. Klopf, T.A. Nieman, Anal. Chim. Acta 341 (1997) 195. 


\section{Supplementary data.}

Appendix A. HPLC-DAD blank chromatograms of an irrigation water sample at different wavelength: a) $200 \mathrm{~nm}$; b) $222 \mathrm{~nm}$; d) $250 \mathrm{~nm}$.
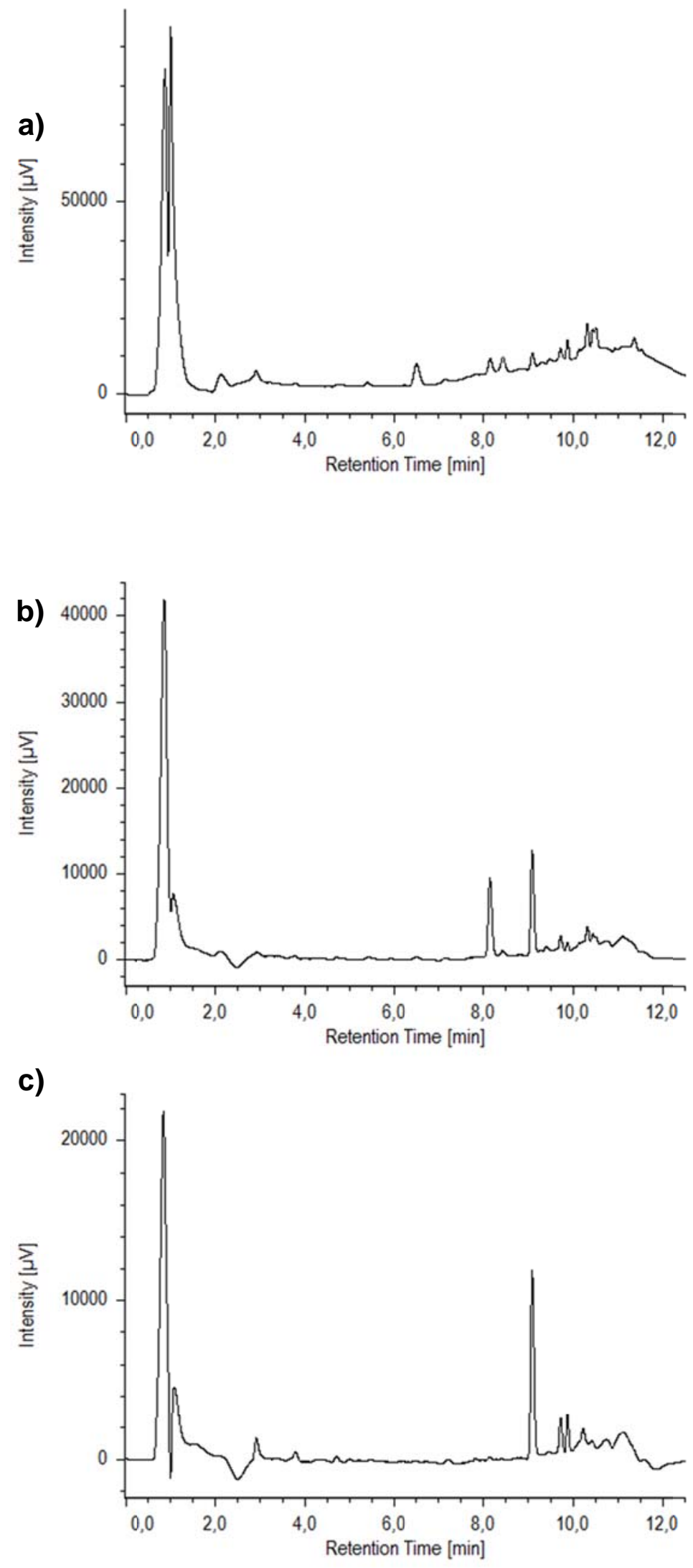